\title{
(NO) SEGUIR BUSCANDO A MAMÁ. PERFORMANCE Y POSMEMORIA EN CAMPO DE MAYO DE FÉLIX BRUZZONE
}

(Do not) keep looking for mom. Performance and postmemory in Campo de Mayo by Félix Bruzzone

\author{
MARIELA PELLER \\ Consejo NaCiOnAL DE INVESTIGACIONES CiENTÍFICAS Y TÉCNICAS (CONICET) \\ UNIVERSIDAD DE BUENOS AIRES (UBA) (ARGENTINA) mariela_peller@hotmail.com
}

RECIBIDO: 18 DE DICIEMBRE DE 2017

ACEPTADO: 13 DE MAYO DE 2018

REsumen: En este artículo analizo Campo de Mayo. Una conferencia performática de Félix Bruzzone, quien es escritor e hijo de desaparecidos durante la dictadura militar argentina. Considerando las propuestas de Marianne Hirsch sobre posmemoria y de Diana Taylor sobre performance, sitúo el sentido de la performance en el contexto de la producción literaria de Bruzzone e indago en las aperturas que habilita la forma performática al trabajo de elaboración del duelo. La proliferación de desvíos durante la performance le permite a Bruzzone repetir y ampliar una estructura de deseo de búsqueda ya presente en su obra literaria, en tanto que las imágenes fotográficas (principalmente la imagen materna) operan mediante un lenguaje de género que, en su encuentro con el público, posibilita una expansión desde una posmemoria familiar hacia una afiliativa. Por otra parte, las figuras de la repetición en la performance (el juego, la continuidad, el doble) funcionan habilitando un trabajo de elaboración de la pérdida. Finalmente, reflexiono sobre las posibilidades de reparación que se producen en el encuentro con otros que se genera en la escena de la performance

PALABRAS ClAVE: Posmemoria, performance, dictadura, Félix Bruzzone, segunda generación.

ABSTRACT: This article inquires Campo de Mayo. Una conferencia performática by Felix Bruzzone, who is a writer and son of two disappeared during the last Argentinean military dictatorship. Considering Marianne Hirsch's proposals on postmemory and Diana Taylor's on performance, the text exposes the effects that the conference produced in contrast with Bruzzone's previous literary works. The article suggests that certain characteristics of the structure of performance, like repetition and interaction with the public, allows Bruzzone to make three operations: expand a research structure that was already present in his literature (which is called search desire); work on the elaboration of loss; and generate a displacement from a familial to an affiliative postmemory. In the last point, the photo of the missing mother plays a fundamental role. Finally, the article presents a reflection about the possibilities of reparation which are produced in the encounter with the public and the actors during the performance scene.

KEYWORDs: Félix Bruzzone, Postmemory, Performance, Dictatorship, Second Generation.

Peller, Mariela.

“(No) seguir buscando a mamá. Perfomance y posmemoria en Campo de mayo de Félix Bruzzone”.

Kamchatka. Revista de análisis cultural 11 (Julio 2018): 419-440

DOI: 10.7203/KAM. 11.11221 ISSN: 2340-1869 
"Si no se detuvo es porque debe seguir, y es lo que hace." Félix Bruzzone

\section{INTRODUCCIÓN}

Campo de Mayo. Una conferencia performática de Félix Bruzzone se estrenó en 2013 como parte de $M i$ is documentos, un ciclo de conferencias curadas por Lola Arias, en el cual según la directora artistas de disciplinas diversas exhiben "una investigación personal, una experiencia radical, una historia que los obsesiona secretamente". ${ }^{1}$ Prontamente el proyecto se independizó de la dirección de Arias y comenzó a montarse con la colaboración de Mariana Mazover. En esa nueva etapa, la obra se exhibió en una variedad de escenarios: salas de teatro, universidades, museos y centros culturales.

Bruzzone nació en agosto de 1976, durante la última dictadura militar argentina (1976-1983), es hijo de Marcela Bruzzone y Félix Roque Giménez. Lleva el apellido materno porque cuando nació, su padre ya estaba desaparecido. Su madre desaparecería en noviembre, tres meses después. Ambos eran militantes del PRT-ERP.2 Bruzzone es escritor, editor y trabaja limpiando piletas. Ha publicado el libro de cuentos 76 (2007), las novelas Los topos (2008), Barrefondo (2010) y Las chanchas (2014) y, recientemente, un libro de relatos sobre su experiencia como piletero, Piletas (2017).

La conferencia performática trata sobre la relación de Bruzzone con Campo de Mayo, una de las guarniciones militares más grandes del país, situada en la zona norte de la provincia de Buenos Aires, en la que, durante la dictadura, funcionaron varios centros clandestinos de detención. ${ }^{3}$ En una zona cercana a Campo de Mayo vive Bruzzone desde 2006, en una casa que construyó en un terreno comprado con dinero que recibió de la indemnización por la desaparición de su madre. Campo de Mayo es también el lugar en el que su madre estuvo viva por última vez.

Desde que asistí a la obra en el teatro la Carpintería, ya bajo la dirección de Mazover, me llamó la atención la continuación de la exhibición de la performance. ¿Por qué Bruzzone, un

\footnotetext{
1 Extracto tomado de la presentación del proyecto Mis documentos en la web de Lola Arias, quien es argentina, escritora y directora de teatro. Las obras de Arias se caracterizan por cruzar ficción y realidad. Cfr. http:// lolaarias.com/proyectos/mis-documentos-2/.

2 El Ejército Revolucionario del Pueblo (ERP) surgió en 1970 como brazo armado del Partido Revolucionario de los Trabajadores (PRT), partido trotskista fundado en 1965 y liderado por Mario Roberto Santucho. La primera operación (exitosa por realizarse por sorpresa), fue a principios de 1973 con un ataque y copamiento del Batallón 141 de Córdoba, con el cual nació la primer Compañía Urbana del ERP: la Compañía Decididos de Córdoba (Pozzi, 2001). Félix Roque Giménez tuvo un puesto clave en este operativo. Fue secuestrado en marzo de 1976 y detenido en el centro clandestino Campo de la Ribera, se encuentra desaparecido desde entonces. Marcela Bruzzone desapareció en noviembre de 1976, fue secuestrada en su domicilio en un operativo del Ejército y también continúa desaparecida (Arenes y Pikielny, 2016).

${ }^{3}$ La guarnición militar Campo de Mayo fue utilizada durante la última dictadura militar argentina para coordinar el accionar represivo de una amplia zona del Conurbano Bonaerense llamada Zona 4 que abarcó desde Vicente López, San Martín, San Isidro, San Fernando, Tigre, Tres de Febrero hasta General Sarmiento (hoy partidos de San Miguel, José C. Paz y Malvinas Argentinas). La Guarnición articuló una cárcel, una maternidad clandestina y varios Centros Clandestinos de Detención: Las Casitas, La Escuelita, El Campito (Vecchioli et al., 2016).
} 
escritor hijo de desaparecidos, decide seguir haciendo la conferencia performática tras haberla realizado por primera vez en el ciclo de Arias?, ¿por qué se le manifiesta el deseo de continuar realizando la conferencia, de volver a poner el cuerpo una y otra vez?, ¿qué motivos podrían llevarlo a desplazarse -al menos por un momento- de la literatura a la performance? En suma, ¿qué posibilidades le habilita a Bruzzone la forma performática?4

En este artículo intento responder estas preguntas a través del análisis de la performance Campo de Mayo como un objeto de posmemoria autoficcional. Para ello sitúo el sentido de la performance en el contexto de la producción literaria de Bruzzone, pero también indago en las aperturas que produce la forma performática al trabajo de posmemoria y de elaboración del duelo. En el primer apartado presento las nociones de posmemoria y autoficción, para dar cuenta de las potencialidades que tienen para el análisis de las producciones estéticas de las hijas e hijos de desaparecidos en Argentina. En el segundo apartado, reflexiono sobre los modos en que ciertas características de la performance le permiten a Bruzzone repetir y ampliar una estructura ya presente en su obra literaria, que denomino deseo de búsqueda. En tercer lugar, estudio las imágenes presentes en la performance y cómo operan mediante un lenguaje de género para producir una expansión hacia una modalidad afiliativa de la posmemoria. En este punto, refiero principalmente a los significados de la presencia de una fotografía de la madre. En cuarto lugar, estudio las figuras de la repetición en la performance (el juego, la continuidad, el doble) y cómo funcionan habilitando un trabajo de duelo. Finalmente, en el cierre reflexiono sobre las posibilidades de reparación que se producen en el encuentro con otros que habilita la performance.

\section{POSMEMORIA Y AUTOFICCIÓN}

Las nociones de posmemoria y autoficción son fundamentales para la comprensión de las intervenciones culturales y simbólicas de la generación de las hijas y los hijos de desaparecidos en Argentina. ${ }^{5}$ El comienzo de estas intervenciones suele situarse en 1995 con el nacimiento de la agrupación HIJOS (Hijos e hijas por la Igualdad y la Justicia contra el Olvido y el Silencio), conformada por hijos de detenidos-desaparecidos, que estableció una discursividad estética como estrategia principal en sus operaciones políticas (Dalmaroni, 2004). La serie de producciones simbólicas, no todas vinculadas directamente con la agrupación HIJOS, es cada vez más extensa y se compone de una diversidad de registros, géneros e intervenciones: relatos literarios, films ficcionales y documentales, ensayos fotográficos, obras teatrales y performances. Estos jóvenes, afectados por el terrorismo de Estado, eligen al arte como vía privilegiada para indagar sobre el pasado de sus padres forjando un segmento de narrativas generacionales que pone el foco críticamente no sólo en la violencia catastrófica llevada adelante por la dictadura sino también en

\footnotetext{
${ }^{4}$ En abril de 2018 Félix Bruzzone participó en una nueva obra de performance. Se trató de "Cuarto intermedio: Guía práctica para audiencias de lesa humanidad”, en la que estuvo acompañado por Mónica Zwaig, bajo la dirección de Juan Schnitman. La obra se presentó en el marco del ciclo "Literatura expandida", organizado por el Fondo Nacional de las Artes de Argentina. El ciclo reflexionaba sobre los desplazamientos de la literatura hacia otros lenguajes y cómo esos vínculos permiten su renovación.

5 Son aquellas generaciones nacidas entre fines de los años sesenta y principios de los ochenta, quienes fueron niños (y en algunos casos adolescentes) durante la dictadura y que vivieron sus años de juventud en la postdictadura.
} 
la organización de la vida cotidiana y en las opciones políticas y personales tomadas por la generación de sus padres. Más allá de su heterogeneidad y su dispersión, estas obras poseen algunas características comunes: configuran nuevos modos de entender la relación entre lo público y lo privado, entrecruzan los registros de la autobiografía con la ficción, se posicionan desde la interdisciplinariedad y conforman una memoria lúdica, desacralizada y no solemne (Blejmar y Fortuny, 2013). De esta manera, las obras consideradas han habilitado -tanto por su dimensión temática como formal- lecturas desde las categorías de posmemoria y de autoficción.

El término posmemoria surge a fines de los años ochenta dentro de los estudios de memoria para analizar artefactos culturales que trabajan sobre la perdurabilidad, la transmisión y la memoria de experiencias traumáticas a través de distintas generaciones. La noción fue elaborada primeramente por la crítica literaria norteamericana, Marianne Hirsch, en el marco de su estudio sobre la transmisión intergeneracional de experiencias traumáticas en objetos culturales producidos por la segunda generación del Holocausto, es decir, por los hijos de los sobrevivientes (Szurmuk, 2009). Hirsch formuló la noción en su libro Family Frames (1997), en el que analizaba los usos de la fotografía en procesos de posmemoria familiar, aquella que va de padres/madres a hijos/hijas y se mantiene dentro del ámbito de la familia. También señalaba allí que la posmemoria supone un trabajo de elaboración crítico, imaginativo y artístico sobre los relatos heredados. Tras esta primera versión, la autora fue reformulando la noción. En "Surviving Images" (2001) se basó en el pensamiento de Dominick LaCapra (2005) para estudiar los modos en que el uso repetitivo de imágenes puede habilitar en la posmemoria un trabajo de elaboración del trauma en la segunda generación. Luego, en "The Generation of Postmemory" (2008) con la noción de posmemoria afiliativa, amplió la idea de posmemoria para pensarla como un proceso que se desencadena no solo dentro del círculo familiar sino también en otros espacios sociales. La noción se fue reformulando hasta adquirir ciertas características que la tornan adecuada para trabajar sobre las posmemorias de las hijas y los hijos de desaparecidos en Argentina, y particularmente sobre la performance Campo de Mayo.

En primer lugar, la idea de posmemoria supone un vínculo específico con el pasado que lo diferencia de la memoria. Si bien se trata de una "conexión viva", es una relación mediada (por imágenes, relatos de otros, silencios, acciones, síntomas), aunque en muchos casos se presente para el sujeto como un recuerdo propio. Es en este nivel que las imágenes fotográficas ocupan una función central como objetos de transmisión y mediación de las memorias entre las generaciones. Quienes no vivieron el acontecimiento traumático, sino que lo recuerdan por medio de los relatos de las generaciones previas o de las imágenes fotográficas disponibles, tienen un vínculo mediado con el pasado. Inspirada en el pensamiento de Roland Barthes (2005) sobre la fotografía y sus vínculos con la muerte, principalmente, las referidas a la capacidad de las imágenes fotográficas de evocar que "esto ha sido", Hirsch señaló que las fotografías eran una pieza clave en los trabajos de posmemoria. A través del análisis de las fotografías presentes en la historieta Maus de Art Spiegelman, Hirsch sostuvo que las fotografías familiares poseen una fuerza evocativa por la evidencia de la existencia del referente en el pasado y también por su capacidad de probar los lazos de sangre entre el ausente y su descendencia. Asimismo, los sentidos sociales dados a ciertas imágenes tienen la capacidad de postular identificaciones afectivas con los espectadores abriendo el campo de la posmemoria afiliativa. En este sentido es 
que la posmemoria supone un vínculo performativo con el pasado porque las lecturas sobre los materiales heredados están formadas por los deseos, las necesidades y la imaginación del espectador o del escucha más que por el haber estado allí del protagonista o del testigo.

En segundo lugar, la noción de posmemoria implica un modo específico de entender la transmisión de experiencias traumáticas y la posibilidad de elaboración por parte del sujeto. Posmemoria refiere una estructura de transmisión de memorias entre generaciones que focaliza su mirada en los herederos. Se ocupa de los registros culturales producidos por generaciones marcadas por acontecimientos traumáticos que no vivieron directamente, pero por los cuales todavía intentan realizar el duelo. Hirsch (2001) sugiere que quizás sea sólo en las generaciones subsecuentes que el trauma puede ser elaborado, porque la posmemoria como práctica artística tiene la capacidad de producir nuevos textos y nuevos contextos sobre los materiales heredados.

Tercero, si en la primera versión del término la familia se presentaba como el espacio social privilegiado del trabajo de posmemoria, en sus análisis posteriores Hirsch comenzó trabajar sobre la idea de una posmemoria afiliativa. Se trata de una modalidad de posmemoria que muestra que quienes no son familiares de los afectados directos se involucran también en el proceso de recuperación del pasado y se sienten interpelados por los eventos traumáticos. La posmemoria familiar (aquella que se produce de un modo vertical entre padres e hijos) se desplaza así hacia otros espacios y habilita actos de transmisión entre aquellos que no forman parte del círculo cercano a los afectados. Este tipo de posmemoria se produce de modo horizontal mediante el contacto entre la segunda generación y sus contemporáneos (los integrantes de la generación de posmemoria), en colaboración con una serie de relatos e imágenes culturales disponibles sobre el pasado. Se produce así una red de transmisión más amplia (Hirsch, 2012:36).

Estos puntos del concepto de posmemoria permiten realizar articulaciones con la noción de autoficción. Anna Forné, considerando el caso argentino, elaboró la noción de "posmemoria autoficcional" para pensar sobre los procedimientos y posicionamientos subjetivos que comparten la posmemoria y la autoficción. Para esta autora, la "posmemoria autoficcional se caracteriza por una proyección de las memorias heredadas en una suerte de proceso creativo de recuperación, articulado por medio de la imaginación y desde una subjetividad en construcción fuertemente perfilada como el motor del relato de búsqueda" (2014:116). ${ }^{6}$

Las narrativas autoficcionales colaboran en el trabajo de la posmemoria porque posibilitan un trabajo con el pasado heredado y a la vez una apertura al presente. Trabajan con fragmentos,

\footnotetext{
6 A diferencia de Forné que decide usar el término posmemoria en el contexto de la última dictadura militar argentina, existen otras investigaciones que cuestionan la pertinencia del término para describir las producciones culturales de hijas e hijos de desaparecidos. La crítica más potente se dirige a la cuestión de que estas hijas e hijos no pueden entenderse como pertenecientes a una segunda generación como en el caso del Holocausto. Por el contrario, se trata de protagonistas o testigos en primera instancia, víctimas directas con recuerdos propios sobre los acontecimientos violentos del pasado, que en muchos casos estuvieron presentes en el secuestro de sus padres, estuvieron ellos mismos secuestrados, fueron apropiados o nacieron en cautiverio. Según las críticas, en estos casos no puede hablarse de una experiencia traumática heredada a través de lógicas de transmisión intergeneracional, sino que se trata de una vivencia plena (Pérez, 2013; Ciancio, 2015; Blejmar, 2017). Beatriz Sarlo (2005) había cuestionado previamente la noción de posmemoria en el marco de una crítica generalizada a lo que denominó el "giro subjetivo". A diferencia de las críticas actuales que se dirigen hacia sus usos situados, la crítica de Sarlo apuntaba a la innecesaridad del concepto. Para Sarlo las mediaciones con respecto al acontecimiento traumático no son exclusivas de la posmemoria, sino que refieren a características de todas las formas de memoria, incluida la de los protagonistas.
} 
restos y discontinuidades que son los materiales de la posmemoria. Escribe Régine Robin sobre este tipo de escritura del yo: "Escritura trabajo de duelo, a la vez de deconstrucción de la ilusión biográfica y de reconstrucción, elaboración de un lugar distinto no aleatorio, lugar de verdad. Esta sería la tarea imposible de este objeto inasible que es la autoficción” (2002: 54).

Para Robin (1994) la necesidad de justificar una identidad por medio de una autoficción surge cuando ésta se ve amenazada, por ejemplo, en los casos en que la transmisión entre generaciones fue cercenada por escenarios de violencia. Una autoficción se produce cuando un texto pone en escena la imposibilidad de la narración misma, cuando el artista sin dejar de narrarse a sí mismo, es consciente de la parte de ilusión que produce en la narración de sí. Desde esta perspectiva, una autoficción es una autobiografía consciente de su imposibilidad, porque permite la búsqueda de la identidad a través de un desplazamiento de posiciones subjetivas, de la huida de la unicidad para hurgar más bien en los fragmentos, las rupturas, las faltas, las discontinuidades, atendiendo no solo a la propia vida sino también al proceso de escritura en sí mismo (Corbatta, 2009; Doubrovsky, 2012).

Leonor Arfuch (2007) señala que estas textulidades híbridas forman parte de un "espacio biográfico" que es el resultado de una tendencia de la cultura contemporánea a la revalorización de la subjetividad. En ese universo más amplio, la autoficción se caracteriza por ser un relato que no se pretende verídico, aunque posee marcas de autenticidad. Porque si bien se construye con procedimientos ficcionales, permite identificar por medio del nombre propio al autor, al narrador y al personaje. En Argentina, fueron los relatos sobre la violencia del pasado reciente producidos por la generación de hijas e hijos los que adoptaron una perspectiva autoficcional. Previamente, las voces de la generación de los militantes - los progenitores, los protagonistas- se habían producido desde un registro testimonial. "En este sentido, la voz de los hijos es a la vez memoria proyectiva e interpretación del pasado pero con un fuerte anclaje en el presente, donde el trabajo de duelo -al que sin duda aporta la creación artística- parece ganar terreno a la melancolía" (Arfuch, 2008:169).

En suma, la autoficción es un procedimiento estético narrativo que está al servicio de la posmemoria porque permite elaborar, aunque de forma precaria y fallada, el duelo por las pérdidas acontecidas. En la autoficción la imaginación y la creación tienen un lugar central porque permiten suplir las contrariedades de la historia, los huecos y las ausencias, dando sentido desde el presente a ese pasado heredado. Los usos de la autoficción por parte de integrantes de la generación de posmemoria en Argentina se vinculan con la experiencia de ser hijos e hijas de desaparecidos, que supuso una falta de saber sobre sus orígenes y sus filiaciones, un escamoteo de información que los condujo hacia una condición de búsqueda constante (de información, del cuerpo de los padres, de cierto saber sobre sí mismos y sus progenitores) y la consiguiente necesidad de elaboración de un trabajo de duelo. Estas estrategias narrativas están presentes en muchas de las obras de la generación de posmemoria en Argentina y en particular en las de Félix Bruzzone (Blejmar, 2016; Fandiño, 2016; Peller, 2016; Logie, 2015). Tomando las consideraciones previas, en este artículo intento comprender los modos en que autoficción y posmemoria se despliegan en la performance Campo de Mayo. 


\section{LOS DESVÍOS Y EL DESEO DE BÚSQUEDA}

El montaje de la performance Campo de Mayo es mínimo y mantuvo la huella de la dirección de Arias, que trabaja de modo minimalista, solo con actores y objetos en el escenario. ${ }^{7}$ En el lado derecho del escenario hay un escritorio con una notebook; en el centro, una pantalla y en el lado izquierdo, un perchero con ropa y algunos objetos colocados en el piso. En el escritorio, sentados uno al lado del otro, están Bruzzone y Lucas Balducci, actor que cumple el rol de asistente. Bruzzone tiene entre sus manos unos papeles que lee y su asistente maneja la computadora en la que están las imágenes y los audios que se exhiben en una pantalla a lo largo de la obra.

Uno de mis objetivos en este artículo es indagar en los motivos (intencionales o no) por los cuales Bruzzone continuó realizando la performance tras su primera presentación bajo la dirección de Arias. Me interesa comprender qué posibilidades le dio el lenguaje de la performance. En este sentido, Diana Taylor, especialista en el análisis de performances, sugiere que para entender de qué se trata este tipo de arte es mejor preguntarse por las aperturas que genera más que por lo que es en sí mismo. Según la autora, “en lugar de preguntarnos ¿qué es o no es performance? hay que preguntarse ¿qué nos permite hacer y ver performance, tanto en términos teóricos como artísticos, que no se puede hacer/pensar a través de otros fenómenos?” (2011: 15). ${ }^{8}$ A partir de esta pregunta de Taylor, quiero reflexionar sobre las posibilidades que la performance le aporta al trabajo de posmemoria, que Bruzzone ya venía realizando en su obra literaria. ¿Cuál es el plus o la diferencia que este formato artístico le posibilita? ¿Cómo se relaciona el arte de performance con los temas específicos de la obra de Bruzzone, especialmente con 76 y Los topos?

76 se compone de ocho cuentos que abarcan diversos contextos y temporalidades de la vida de un hijo de desaparecidos (la niñez, la adolescencia y la adultez) narrando una variedad de experiencias de la vida cotidiana. Los relatos van desde los problemas con amigos durante unas vacaciones en la playa durante la infancia con una abuela que lo crío hasta los recuerdos del padre en una especie de road movie en la búsqueda de un camión Unimog para comprar. La cuestión de los padres desaparecidos reaparece constantemente también en aquellos relatos que no refieren en ningún momento a episodios trágicos. El libro compone una especie de "novela fragmentada" (Premat, 2017) ya que en cada relato abarca zonas experienciales diversas pero conforma una unidad.

\footnotetext{
7 Lola Arias dirigió otras obras teatrales referidas a la memoria del pasado reciente argentino, que presentan características autoficcionales. Mi vida después (2009) y Campo minado (2016) se elaboraron a partir de las memorias de personas reales. En el primer caso, se trata de las historias de hijas e hijos de integrantes de la generación de los años 70; en el segundo, se ponen en escena los recuerdos de veteranos argentinos e ingleses de la guerra de Malvinas (1982). En ambos casos, no se trata de actores que interpretan la vida de otros sino de personas que ponen en escena su propia memoria biográfica e histórica.

8 Más allá de enfocar el interés por este arte en las aperturas formales que produce, Taylor (2011) describe a la performance y sus orígenes. Para la autora, se trata de un tipo de arte que nació en las décadas del sesenta y setenta, cuestionando los lazos institucionales y económicos que excluían a los artistas de teatros, galerías y espacios de arte. En ese contexto crítico el artista usaba su cuerpo para interpelar y cuestionar a las instituciones, haciendo apariciones inesperadas y llamativas que en muchos casos eran efímeras y sorprendían al público. Para hacer performance solo se requería del artista, su cuerpo, la creatividad y el público.
} 
En Los Topos el protagonista también es un hijo de desaparecidos que se niega a integrarse a la agrupación HIJOS, y que sospecha -por los comentarios de su abuela- que su madre podría haber tenido otro hijo en cautiverio. El protagonista imagina que Maira, una travesti a la que comienza a frecuentar, podría ser su hermano apropiado. Pero también sospecha que Maira podría ser un doble agente y un vengador de policías. La búsqueda de Maira lo lleva a Bariloche donde en lugar de encontrar al hermano perdido, él mismo se hace travesti y comienza a tener una relación con el Alemán, un ex represor, de quien finalmente se enamora.

El tema central y la estructura de estas obras se vincula con la búsqueda. Se trata de una búsqueda llena de desvíos y derivas, son búsquedas que no logran alcanzar su objeto. El protagonista siempre está frente a la imposibilidad de encontrar lo que está buscando (Sarlo, 2012; Basile 2016). Son también búsquedas que implican un tiempo de eterno retorno, que se repiten una y otra vez. Son búsquedas que implican digresiones insospechadas, que parecen estar al servicio del sostenimiento al infinito de la condición de búsqueda. "Lo que el narrador busca está en el presente de su historia, aunque su motivación subjetiva, el motor que lo pone en condición de buscar, esté en el pasado”, escribió Beatriz Sarlo sobre Los topos (2012: 54).9

Esta condición de búsqueda se relaciona con la identidad asumida por Bruzzone, que Julio Premat denominó la del "escritor-hijo-de-desaparecidos", que funciona como "un repertorio de posibilidades ficcionales, un procedimiento narrativo, un mecanismo de escritura" (2017: 217). A nivel argumental esa identidad trabaja junto con un "vitalismo narrativo", que supone un seguir adelante ante el vacío de la memoria y las ausencias, transformando lo irresoluble en energía vital y aperturas hacia el futuro. Ante la falta de recuerdos, la respuesta es la literatura y sus posibilidades imaginativas. Ese vitalismo es así un "puro deseo de creación” (229). Premat identifica estos rasgos de vitalismo en los cuentos que componen 76, en el modo de narrar desde lo insignificante, con desvíos hacia lo secundario, sin énfasis precisos, pero con una impresión de trasfondo y profundidad. En Los topos ese vitalismo opera en desplazamientos, mutaciones, derivas y contradicciones, que acercan la novela a un "happening literario constante".

Andrea Cobas Carral (2013) también sostuvo que la imaginación (que por momentos se torna delirio) funciona en la obra de Bruzzone como motor del relato, porque permite ganarle al silencio y a las ausencias. A partir de la proliferación de la ficción, el autor conforma una genealogía para reponer su identidad al mismo tiempo en que produce revisiones sobre los discursos del pasado y la memoria: los organismos de derechos humanos, los militantes, la democracia. Para poder saber -y hablar sobre la indecible- hay que imaginar, sostiene la autora.

Este deseo de búsqueda que caracteriza a la obra literaria de Bruzzone se repite y se expande en Campo de Mayo. En la performance se trata nuevamente de una búsqueda por saber sobre aquello que no se puede saber. Una búsqueda que no logra cumplir su objetivo porque no puede y que por eso mismo se presenta como una búsqueda desviada, por momentos delirante, llena de derivas, en la que la desaparición de los padres (en la obra la figura de la madre cobra

\footnotetext{
9 Una lectura similar realiza Carlos Gamerro cuando afirma que Los topos es una "novela de deriva continua" o de "abandono de la trama", porque en ella Bruzzone produce "una forma textual que sea ella misma una fuga, que siga una deriva a la que el protagonista no tendrá más que abandonarse para terminar en una costa desconocida, mucho más alejada del punto de partida de lo que él mismo hubiera sido capaz de imaginar” (2015: 506).
} 
primacía) está allí como ausencia sobre la que la imaginación se pone a trabajar desde el presente y hacía el futuro, desde ese vitalismo al que se refería Premat.

Estas características de la obra literaria de Bruzzone se expanden y desarrollan en Campo de Mayo. La performance le permite repetir y ampliar ese deseo de búsqueda que ya estaba presente en su obra literaria. En Campo de Mayo se reitera el tema de la búsqueda y sus derivas, como también hay una insistencia en la posición que el sujeto asume en dicha búsqueda. Una posición de distracción al mismo tiempo en que se esperan revelaciones provenientes de personas o lugares insólitos. Una posición que Tamara Kamenszain llamó la del "investigador distraído", la de un narrador que mantiene "un no saber que, sin embargo, no deja de destellar luz" (2016: 103). Como señala Kamenszain, ese tipo de investigador ya había sido desarrollado en "Otras fotos de mamá", cuento del libro 76. En ese relato el protagonista, un hijo de desaparecidos, se encuentra a cenar con Roberto, el ex novio de su madre desaparecida y su actual mujer, Cecilia. Cuando la cena termina, el protagonista lleva a Cecilia a comprar unos tapones de rugby para el hijo, que ella luego pasa a buscar por la casa del protagonista cuando sale de un curso. Cuando Cecilia llega, el protagonista afirma que espera que ella le revele algo fuerte, como que Roberto es su verdadero padre o algo de ese orden, pero en cambio Cecilia se limita a decir que el café está muy rico. Él absorto en la charla olvida pedirle a Cecilia que le recuerde a Roberto que busque las fotos antiguas de su madre desaparecida. Vemos que se trata de derivas que cobran primacía por sobre lo que suponemos es más importante.

Como "Otras fotos de mamá", Campo de Mayo trata de una búsqueda desviada y delirante. Pero esta vez sí accedemos a la fotografía de la madre desaparecida. La imagen de la madre de Bruzzone es una de las primeras que aparece en la pantalla. Bruzzone nos muestra la imagen de la madre desaparecida y narra que parece haber sido allí en Campo de Mayo que se la vio por última vez con vida. Luego pasa a hablar de otras cosas que al público nos parecen secundarias. Nos hablará, por ejemplo, sobre los usos actuales y futuros del predio. Poniendo en práctica un deseo de buscar hacia el futuro afirma en la obra:

Lo primero que supe, entonces, es que mi investigación no iba a ser detectivesca. Y no iba a ser sobre el pasado. Para eso hay libros muy buenos. Testimonios. Fuentes. Elementos variados y complejos que nunca estuvieron a mi alcance. Y además, por alguna razón, la obsesión iba para otro lado. Lo que me interesaba era rearticular mi relación con el lugar. Y preguntarle a otros cuál era su relación con el lugar. Y, puesto que yo y todos los que vivimos cerca probablemente sigamos viviendo allí por mucho tiempo, intentar pensar en el futuro del lugar.

Bruzzone nos hablará de la relación de los vecinos del barrio con el predio y sus instalaciones, de los entrenamientos que diferentes clubes de rugby realizaron en el lugar y también sobre el cálculo de la cantidad de "mierda" que entra en el espacio del CEAMSE10. Estos desvíos resultan inquietantes porque la imagen de la madre -que nos fue mostrada al comienzo- no deja de estar presente en su ausencia. Está, aunque ya no la veamos. Bruzzone nos muestra el motivo de su conexión con Campo de Mayo y luego lo oculta para ocuparse de otras

10 La Coordinación Ecológica Área Metropolitana del Estado (CEAMSE) es una empresa pública argentina encargada de la gestión de residuos sólidos urbanos del Gran Buenos Aires, incluyendo la Ciudad de Buenos Aires y los 34 partidos del Conurbano. 
cosas y poder continuar. Sin embargo, la imagen de la madre queda guardada en nuestra retina durante la obra -y también después cuando ya nos hemos retirado del lugar-. La performance actualiza así esa tensión entre la presencia y la ausencia, entre lo importante y las derivas.

Tras referirse a los modos en que su madre está ausente y presente en el lugar, Bruzzone muestra un mapa de la zona y detalla las actividades y servicios disponibles en la guarnición: instalaciones militares, un matadero, una tosquera, un polígono de tiro, una escuela de equitación, un salón de fiestas que alguna vez fue alquilado por el colegio al que asisten sus hijos y una planta de tratamiento de desechos del CEAMSE. Luego de esta descripción detallada del predio, pasamos a otra deriva relativa al vínculo que los vecinos -algunos clientes a quienes Bruzzone les limpia la pileta- tienen con el lugar. En esta escena es particularmente interesante el caso de José Arce -un ex bancario que decidió mudarse a la zona con su mujer, Susana, huyendo de la ciudadcon quien Bruzzone, a pesar de tratar su discurso con cierta ironía, se identifica. Arce también llegó a Campo de Mayo sin saber muy bien que estaba en esa zona a la que odiaba, cuenta que había hecho la "colimba"11 allí, durante su adolescencia y se había jurado no volver nunca más y al poco tiempo de mudarse descubrió que su hogar actual está ubicado a pocas cuadras de Campo de Mayo.

La última deriva es la relativa a los clubes de rugby que hacen entrenamientos especiales en Campo de Mayo. Bruzzone nos cuenta que, por medio de un primo rugbier, se enteró de que los equipos van a la guarnición a entrenarse con técnicas militares: carreras cargando troncos, ejercicios de flotación en piletas y hundimiento, sorteo de obstáculos en campos minados. Para tratar de comprender los vínculos actuales entre los militares y ese deporte, Bruzzone entrevistó al teniente, que realiza los entrenamientos ${ }^{12}$.

Estos desvíos parecen tener una doble función. Porque desviarse es la forma de no buscar allí donde se debería, pero también es la forma de no parar de buscar. Los desvíos hacen que la búsqueda nunca concluya, hacen que se deba seguir adelante hacia el futuro, con esa energía vitalista que mencionaba Premat. En una entrevista Bruzzone habla sobre la ambivalencia entre búsqueda y desvío que caracteriza tanto a su obra como a la relación con sus padres desaparecidos, se trata de un deseo de "buscar pero no querer encontrar" (Arenes y Pikielny, 2016). Los desvíos están para que la búsqueda no se detenga, para seguir adelante, aunque no se quiera encontrar o se sepa que no hay nada que se pueda descubrir. Dice Bruzzone sobre Campo de Mayo: "Lo que pasó no se puede saber. Este proyecto es una forma de marcar lo que no se puede saber; es la otra cara de la hoja. Está cerquita de lo que fue, pero no es. En mis cuentos y en Los topos, los personajes se desvían por caminos aledaños a lo que pasó. Y yo hago lo mismo" (Yaccar, 2016).

\footnotetext{
11 "Colimba" es la denominación popular dada al Servicio Militar Obligatorio que rigió en la Argentina hasta el año 1994, que debían cumplir los varones entre los 18 y los 21 años.

12 Bruzzone publicó una crónica en la revista Anfibia donde reflexiona sobre el porqué de la existencia de este vínculo entre el rugby y los militares. "Campo de Mayo: cómo quebrar un rugbier".
} 


\section{LA IMAGEN DE LA MADRE}

Si en lugar de atender al texto de la performance, entramos a la obra a través de las imágenes que se exhiben, podemos observar que hay dos series y una imagen que sobresale entre ellas y las separa. Es la imagen de la madre de Bruzzone que funciona como el punctum descripto por Roland Barthes en La cámara lúcida ([1980]2005), como aquello que en una fotografía nos punza, nos agujerea, nos pincha. Y que cobra mayor fuerza porque enfatiza el noema de la fotografía -algo así como su esencia- que el autor describió como el "esto ha sido". En la fotografía de la madre de Bruzzone se hace presente su existencia en el pasado. La imagen da cuenta de que ese referente existió (la madre estuvo viva) y de que alguien estuvo allí sacando esa foto. Se hace también presente su muerte. La imagen no deja de testificar una ausencia, que es una muerte antes de tiempo, una desaparición. El noema se lee así en toda su intensidad. En la imagen la madre tiene 17 años, es más joven que su hijo en el momento en que éste pone en escena la obra. En ese cruce de tiempos y espacios que posibilita la presencia de la fotografía, el hijo deviene una especie de padre de su madre.

La conexión entre referente e imagen torna a la fotografía un medio privilegiado en los trabajos de posmemoria porque evidencia la existencia de lo que ya no está y exhibe el vínculo entre generaciones. Las fotografías familiares poseen un fuerte poder simbólico, evocativo y representacional porque nos remiten al pasado. Pero el poder de las fotografías no proviene solo de que remiten al pasado sino también de que producen conexiones afectivas y sensaciones corporales en los espectadores en el presente, cuando esas imágenes son vistas e interpretadas desde los deseos y necesidades actuales. La puesta en circulación pública de imágenes íntimas y familiares produce mayor identificación y proximidad con los espectadores, a diferencia de lo que ocurre con otro tipo de imágenes públicas sobre los sucesos. La fotografía muestra así su importancia en la conexión entre posmemoria familiar y afiliativa (Hirsch, 2008).

Campo de Mayo comienza con Bruzzone sentado en un escritorio mientras habla sobre su casa en Don Torcuato, en las cercanías de Campo de Mayo. Narra que se compró la casa con el dinero de la indemnización por la desaparición de su madre y que al segundo día de mudanza sonó el teléfono y atendió su mujer, que le pasó el tubo para que hable con Mónica, una ex compañera de colegio de su madre que le contó que en el Nunca Más dice que su madre estuvo detenida en Campo de Mayo. El relato avanza mientras en la pantalla vemos fotografías actuales de la casa, del exterior, del interior, de una plaza cercana. Luego vemos las paredes de la casa con cuadros y una fotografía en blanco y negro de una niña (¿será la madre?). La próxima imagen es del escritorio en el que trabaja Bruzzone, arriba del escritorio hay portarretratos con fotografías en blanco y negro, que conforman una especie de panteón familiar. De izquierda a derecha nos encontramos con una fotografía antigua, de los años sesenta o setenta, de una pareja con un bebé de un año en brazos. También, una imagen de una pareja que parece estar casándose en los años setenta (¿serán sus padres con él? ¿`serán sus padres casándose?).13 Más adelante, en primer plano, la fotografía de un niño de unos dos o tres años de edad arriba de una bicicleta, un poco más

\footnotetext{
13 Sabemos por palabras de Bruzzone dichas en otros contextos que no se trata de sus padres, pero si no poseemos ese saber previo podemos dudar al respecto. Bruzzone ha contado que no tiene fotos con sus padres ni de ellos dos solos juntos, además de que Bruzzone tenía solo tres meses cuando su madre desapareció (Arenes y Pikielny, 2016).
} 
atrás en un portarretrato circular la foto carnet de un varón joven (quizás sea el padre) y, por último, más a la derecha, una imagen color sepia gastada de una mujer joven de pelo largo sonriendo a cámara. Esa fotografía pasará a ocupar en la próxima imagen la totalidad de la pantalla. Solamente de esa fotografía Bruzzone nos dirá de quién se trata. Nos contará que es su madre en 1970, a los 17 años y que la foto fue tomada por una amiga en unas vacaciones en Córdoba. ${ }^{14}$ Se referirá a ese momento como "el comienzo del fin de los tiempos felices", luego su madre empezará a militar, hará entrenamientos militares y se proletarizará, nos dice. Pero en esa foto, que el sol de Campo de Mayo fue borrando y emblanqueciendo, él ve a su madre "fuerte, decidida, y todo lo hermosa que dicen que era". También nos cuenta que la amiga de la madre le dejó otra imagen de ella, se trata de un relato que las recuerda haciendo dedo de noche en una ruta, las levanta un camión y luego las deja en el medio de la ruta solas.

La primera serie de imágenes se conforma con fotografías de su hogar actual, de sus familiares, de su madre y de un relato en el que su esposa (quien sabemos es hija de una prima segunda de su madre), y las amigas de su madre están presentes, dando noticias y colaborando en la conformación de la imagen materna. Esta serie remite a un conjunto de significaciones que se asocian con lo femenino: el interior, lo doméstico, el hogar, la familia. Tras la ampliación de la foto de la madre en la pantalla, que cumple el papel de límite, pasamos a una segunda serie de imágenes, comenzamos a ver Campo de Mayo desde otra perspectiva: un territorio exterior, deportivo, masculino y militarizado.

En esta segunda serie las fotografías son de los exteriores de Campo de Mayo, de sus árboles, del verde del césped, de las calles, de las señaléticas. A partir de ese momento, ya no habrá más presencia femenina en la obra, salvo por "Susy" la esposa de uno de los entrevistados, que hablará muy poco mientras Bruzzone entrevista a su marido, y que queda mal parada, como alguien que no entiende los códigos militares. Las entrevistas a los clientes a quienes Bruzzone les limpia la pileta son todas a varones, también son varones los entrevistados militares relacionados con el entrenamiento de equipos de rugby, finalmente la ficción con la que cierra la obra tiene como único personaje a un corredor varón. También las voces que escuchamos durante esta segunda parte son todas masculinas, mientras que las mujeres aparecían al comienzo, unidas al espacio de la casa, del hogar, de la familia y la vida cotidiana. Se produce una disyunción entre las dos series. La imagen de la madre desaparecida es la que separa y a la vez nos adentra hacia la otra dimensión de Campo de Mayo, un territorio masculino y militar.

En un movimiento que recupera y explota ciertos discursos sociales sobre las mujeres militantes, como su belleza, su valentía, su calidad de ninfas y una confusa pertenencia a los

\footnotetext{
${ }^{14}$ La yuxtaposición de Bruzzone sentado en el escritorio con la imagen fotográfica de su madre expuesta atrás nos recuerda la obra de la fotógrafa argentina Lucila Quieto, Arqueología de la ausencia. Quieto es hija de Carlos Quieto, desaparecido por la dictadura militar cuando su madre todavía estaba embarazada. La idea de los retratos de Quieto surgió porque en su álbum familiar no tenía ninguna foto junto a su padre. En Argentina, muchas obras elaboradas por hijas e hijos de desaparecidos incluyen o se producen alrededor de imágenes fotográficas de los progenitores desaparecidos. Análisis críticos sobre las fotografías en las obras de la segunda generación en Argentina se pueden encontrar en los trabajos de Ana Amado (2004) y de Natalia Fortuny (2014).
} 
proyectos revolucionarios, Campo de Mayo construye una imagen materna idealizada. ${ }^{15}$ Separada, deslindada y no contaminada de los horrores de Campo de Mayo. En esa separación entre los dos universos, quien queda en solitario es Bruzzone. Él, el hijo varón, es el único que se desplaza de un territorio a otro, ocupando ambos espacios. Realiza el pasaje solo, sin las mujeres que lo acompañaban y sostenían al comienzo. Quizás sea una lucha entre varones la que deba librarse en el territorio militar que representa Campo de Mayo.

El poder de la imagen de la madre en la performance no proviene solo de su capacidad de intensificar el "esto ha sido" al hacer presente una ausencia, sino que su fuerza se conforma también en el contraste que esa fotografía produce entre las dos series de imágenes, entre los dos universos de Campo de Mayo, que recuperan discursos sociales tradicionales sobre lo femenino y lo masculino. Un universo vinculado a lo femenino, a los afectos, a lo doméstico, al hogar y al interior; otro, relacionado con lo masculino, lo militar, lo deportivo y el exterior. Como espectadores, la fotografía de la madre y sobre todo la escena en la que el hijo está sentado con la imagen de la madre desaparecida detrás nos produce empatía y proyectamos allí la imagen de una familia rota. La fotografía de la madre cobra así su fuerza al evocar rasgos tradicionalmente asociados a lo femenino y a la familia. Que, por otra, parte aparecen como el motivo por el cual el hijo se adentrará en el universo masculino de Campo de Mayo. La posmemoria, dice Hircsh, recurre muchas veces a imágenes con sentidos sociales ya adjudicados, especialmente algunas con marcas de género. De esa manera, el género se torna lenguaje de rememoración (2008).

En una entrevista Bruzzone se refiere a las diferencias entre las representaciones que posee de su madre y de su padre, mientras de ella cree que su final se relaciona con cierta "tendencia suicida", de él mantiene una idea más vinculada al guerrillero heroico, un soldado que traicionó a los propios militares en función de la causa del ERP (Arenes y Pikielny, 2016: 31). En su cuento "Unimog" presente en 76, Bruzzone ya había planteado esta dicotomía entre "la casa" como un espacio vinculado a lo femenino y "lo militar" como un terreno masculino. El protagonista Mota, un hijo de desaparecidos, decide gastar el dinero que el gobierno le dio por la desaparición de su padre para comprarse un camión. Su mujer, Vicky, le advierte que no debería gastar todo el dinero ya que iban a usarlo para terminar la construcción de su casa. Mota desoye a su esposa y compra un camión Unimog, porque le recuerda a su padre desaparecido, quien había participado de la toma del Comando de Comunicaciones del Ejército, robando un camión. Tras una serie de problemas al estilo road movie, el camión se rompe y Mota lo prende fuego. Vicky lo trae de regreso a casa mientras le pregunta si igualmente podrán terminar de construir la casa. A partir de la compra del camión militar se teje una trama de relaciones entre varones de la que Vicky queda afuera. La figura femenina representa, en cambio, la seguridad del espacio de la casa y algo así como una voz de la conciencia.

Si bien en Campo de Mayo el padre de Bruzzone no aparece mencionado explícitamente, su presencia puede ser añadida por el público si conoce su biografía. La figura del padre se asocia con el universo militar masculino, un universo por el cual el hijo siente simultáneamente cierta atracción y repulsión. Esa ambigüedad organiza la obra, en la que Campo de Mayo funciona

\footnotetext{
15 Alejandra Oberti (2015) estudió los modos en que la guerrilla argentina, especialmente el PRT-ERP y Montoneros, construyó en sus discursos una figura de la guerrillera mujer en términos de ninfa, que resaltaba la belleza y el cuidado de los otros, en detrimento de otras características.
} 
como un campo imantado que lo atrae tanto como repele. Si en algunos momentos Bruzzone se burla de los códigos militares, en otros, parece formar parte de ese universo, como lo exhibe la escena en la que se coloca un casco de soldado.

El contraste entre universos, potenciado por la fotografía de la madre desaparecida, opera posibilitando un trabajo de posmemoria afiliativa. Estas imágenes convocan sentidos sociales, que al ponerse en contacto con el público producen la posibilidad de una identificación y comprensión con respecto a los hechos del pasado. Así, quienes no vivieron los hechos traumáticos ni son familiares directos, pueden por medio de su experiencia afectiva con estas imágenes y sus sentidos sociales y familiares construir una conexión con el pasado. Junto con los allegados, pasan a formar parte de una comunidad más amplia de trabajo con la posmemoria, confrontándonos con la idea de que la memoria es a la vez privada y pública, individual y colectiva.

\section{PERFORMANCE, REPETICIÓN Y DUELO}

Una de las especificidades de las obras de performance es ser una repetición de actos. En ellas el comportamiento es re-actuado, re-vivido, re-experimentado de formas que generan aperturas hacia el futuro. Porque la performance "no se limita a la repetición mimética. Incluye también la posibilidad de cambio, crítica y creatividad dentro de la repetición” (Taylor, 2012:17). En la performance el hacer repetitivo posibilita la elaboración de la pérdida porque se trata de una repetición creativa. En ese hacer novedoso surge la posibilidad de tramitar el duelo, para conducir al sujeto hacia la elaboración del pasado "de una manera que abra futuros posibles" (LaCapra, 2006: 167). Para Dominick LaCapra (2006), historiador interesado en los estudios del trauma, particularmente referidos al nazismo, los modos de la repetición en la denominada segunda generación no deben leerse siempre como síntoma, fijeza, parálisis o retraumatizacion sino como un vehículo útil para que el sujeto trabaje en la elaboración del pasado traumático. Esta perspectiva permite entender que no hay posibilidad de generar una narración que pueda integrar completamente el trauma y suturarlo en su totalidad, pero que el sujeto sí puede trabajar para producir aperturas, principalmente a través de la producción de nuevas narrativas sobre lo acontecido. En esta noción de elaboración, la narración, la literatura y el arte juegan un papel importante, como sucede también en la noción de posmemoria de Hirsch. ${ }^{16}$ "Elaborar significa trabajar sobre los síntomas postraumáticos para mitigar los efectos del trauma generando contrafuerzas a la repetición compulsiva (o reactuación) y posibilitando una articulación más viable de emoción y cognición o representación, y también la acción ética y sociopolítica en el presente y en el futuro" (LaCapra, 2006:164).17

\footnotetext{
${ }^{16}$ Hirsch tomó las ideas de LaCapra y señaló que la elaboración del trauma sea quizás solo una posibilidad dada a las segundas generaciones (2001:18).

${ }_{17}$ Teresa Basile recupera las distinciones elaboradas por LaCapra entre elaboración y acting out para su análisis de la obra literaria de Bruzzone, resaltando el modo en que el autor plantea que "ni todo duelo implica el olvido definitivo de lo perdido, ni toda melancolía es pura repetición sintomática" (Basile, 2016: 153). Para una interesante crítica de la lectura que LaCapra hace de Freud y las posibilidades de utilizar sus conceptos para el contexto argentino, se puede consultar el trabajo de Luis Sanfelippo (2013).
} 
La figura de la repetición articula diferentes ejes en Campo de Mayo. Se relaciona con la idea ya trabajada de no poder parar de buscar, pero también con la cuestión de la repetición en la historia, donde la segunda vuelta nunca es igual a la primera -cuestión que aparece principalmente en la ficción del corredor que cierra la obra, sobre la que volveré más adelante-. Por otra parte, la performance en sí misma, en lo que tiene de repetición, de poner el cuerpo y de creación constante, funciona como una metáfora de la continuidad de la búsqueda. Es metáfora y es también vivencia plena, que supone la posibilidad de una elaboración de la pérdida. Seguir haciendo el acto de performance es y no es seguir buscando. Implica la repetición de la desaparición de la madre, pero es a la vez otra cosa - un acto de memoria compartido con otrosque está en el lugar de la pérdida.

En Campo de Mayo la performance como acto repetitivo colabora en la elaboración de la pérdida de la madre. Las ideas de Sigmund Freud ([1920] 2007) sobre la repetición en el juego infantil permiten una interpretación de la repetición y de la presencia de juguetes en la puesta en escena. Cada uno de los episodios que Bruzzone narra es acompañado por juguetes que Balducci coloca en el escenario: pequeños soldaditos de plomo, dinosaurios de plástico, el traje de rugby de un niño, un peluche del muñeco de la película E.T, entre otros.

Freud sugirió la existencia de una compulsión de repetición en los sujetos que se encuentra más allá del principio de placer y que conduce al paciente a repetir en terapia lo reprimido -en muchos casos acontecimientos que le habían causado displacer en su infancia- en lugar de recordarlo. Para comprender esta compulsión de repetición Freud relata su observación del juego de un niño -su propio nieto de un año y medio-. El niño tenía el hábito de arrojar lejos de sí los objetos que se hallaban a su alcance, los arrojaba hacia algún rincón donde se ocultaran de su visibilidad. Al arrojar el objeto el niño profería un fuerte "O-O-O-O", que según los adultos significaba "fort" (se fue). Así el niño, dice Freud, jugaba a que sus objetos "se iban". Pero la observación primordial surgió un día en que el niño tenía un carretel con un hilo y no lo usó para arrastrarlo o para alguna otra actividad, sino que nuevamente lo hizo desaparecer mientras pronunciaba su "O-O-O-o". Luego tirando del hilo lo hizo regresar profiriendo "da" (acá está). Según Freud lo que el niño realizaba mediante esta acción repetitiva era escenificar por sí mismo, con lo que tenía a su alcance, la desaparición y regreso de su madre. Freud encuentra en el juego infantil la repetición de una vivencia que debía ser dolorosa para el niño, la partida de su madre, a la que estaba fuertemente unido y de la que debía soportar su ausencia por largas horas. El niño no sólo repetía activamente lo que debía sufrir cotidianamente de forma pasiva, sino que lo realizaba una y otra vez, como empujado por revivenciar esa penosa experiencia, justamente por su carácter doloroso, es decir, más allá del principio del placer.

En la performance Bruzzone, quien hoy tiene más años que su madre en el momento en que desapareció, retorna en su rol de hijo a una posición infantil y parece jugar el juego descripto por Freud, que mediante la repetición le permite elaborar la pérdida de la madre. Con cada desvío y con cada nueva performance Bruzzone juega con la ausencia y la presencia materna.

La cuestión del juego en la performance y de la incorporación de juguetes en escena, hace serie también con el modo en que muchos artistas integrantes de la generación de postdictadura en Argentina construyen memorias lúdicas, paródicas y no solemnes, permitiéndose "jugar" con el pasado traumático y con el lenguaje. El juego no implica burla ni pérdida de seriedad, sino que 
se vincula con cierta irreverencia contra la dictadura y también contra las instituciones de derechos humanos (Blejmar, 2017). ${ }^{18}$ Desde esa posición de "huérfano paródico" se producen enunciaciones creativas que dan cuenta de la experiencia de ser hijos de desaparecidos al mismo tiempo en que se cuestionan discursos ya naturalizados sobre la memoria colectiva (Gatti, 2011).19 De esta manera junto a las figuras de repetición que entrañan las estructuras del performance y del juego habría que agregar la repetición que supone la noción de parodia presente en la obra de Bruzzone y que está también en Campo de Mayo. Parodiar el pasado es una forma de repetirlo creativamente. 20

En ese juego que es la repetición Bruzzone no está solo. Los espectadores lo observamos jugar, siendo así de alguna manera parte del juego. En efecto, en la mayoría de las funciones al finalizar, se abre un diálogo entre Bruzzone, Balducci y el público. Ellos dos responden las preguntas de los espectadores, que en muchos casos tienen que ver con la obra en sí misma y en otros con la vida de Bruzzone o con su obra literaria (Manduca y Proaño Gómez, 2017).

La repetición aparece en Campo de Mayo no solo como juego o parodia, sino también como continuidad. Esta forma de la repetición aparece explícitamente en la ficción literaria sobre el corredor con la que se cierra la obra. La ficción es la historia de un corredor, una novela que Bruzzone está escribiendo hace tiempo y todavía no logra terminar. En una de las charlas posteriores con el público, Bruzzone explicó que quizás la continuidad de la puesta en escena de la performance no sea otra cosa que un desvío más para no hacer lo que tiene que hacer. Reflexionaba: "quizás cuando termine la novela, termine la performance". ${ }^{21}$ Seguir, continuar, no poder terminar. Obsesionarse. Ese es el tema de la ficción del corredor. Bruzzone cuenta que llegó a la idea de la novela después de leer Nacidos para correr, un best-seller sobre maratones. El libro, dice, comienza a obsesionarlo y "la obsesión deja de ser mamá y pasa a ser correr". Si obsesionarse es una forma de la repetición, aquí la obsesión se desplaza de un objeto a otro en función de un trabajo de elaboración.

En la escena del corredor la figura de la repetición puede leerse desde la idea de autoficción, porque se produce una fragmentación, una multiplicación y un desdoblamiento del yo. Bruzzone, el hijo, piletero, escritor, performer lee su obra de ficción. En la ficción el personaje es un corredor al que podemos identificar con Bruzzone. Es decir, narrador, autor y personaje de la ficción se identifican. A este pacto autoficcional se suma que en la obra es Balducci, el otro

\footnotetext{
18 Jordana Blejmar (2017) encuentra en estas estéticas lúdicas, que se asocian con narrativas autoficcionales, una novedosa formación cultural de la memoria en Argentina.

19 Gabriel Gatti (2011) ha caracterizado a las narrativas de los hijos de desaparecidos, de estos "huérfanos" como "narrativas de la ausencia de sentido" en contraste con las "narrativas del sentido" producidas por los discursos de las agrupaciones de derechos humanos y de los familiares. Estas narrativas de la ausencia se caracterizan por conformar identidades no dependientes de la idea de origen, por la conciencia del carácter construido de toda identidad y por los procedimientos paródicos y disruptivos que presentan.

${ }^{20}$ La parodia es una relación de hipertextualidad que supone la desviación respecto a un texto anterior por medio de una transformación. Dicha operación posee una connotación de sátira o de ironía porque implica un desplazamiento desde un relato épico, trágico o heroico hacia uno cómico o humorístico (Genett,1989). Esta posibilidad de desplazamiento con respecto a relatos heredados es la que hace que sea utilizada en las narrativas de hijos e hijas de desaparecidos (Peller, 2015).

${ }^{21}$ Palabras del intercambio que se desarrolló tras la conferencia performática en septiembre de 2017, en el Centro Cultural de la Memoria Haroldo Conti, en el marco del X Seminario Internacional Políticas de la Memoria.
} 
actor, quien interpreta el papel del corredor, corriendo alrededor de la sala mientras Bruzzone lee su texto. El doble aparece aquí como otra de las formas de la repetición.22Si en las obras literarias de Bruzzone la autoficción estaba presente como eje de lectura, en la obra performática esa clave de lectura se amplía, porque allí Bruzzone es él mismo en escena a la vez en que aparece duplicado y su presencia corporal testifica su vinculación referencial con los recuerdos, hechos e historias que narra. Betina Keizman (2015) señaló que, si bien Campo de Mayo comparte con 76 y Los topos una temática vinculada a la memoria y a la identidad del escritor como hijo de desaparecidos, se distancia de esas dos obras -en las que predominaba un discurso más ficcional y humorístico- por producir un discurso más reflexivo y autobiográfico.

La repetición, en este caso ligada a la continuidad, es también el tema de la ficción. Cuando el corredor se mudó a un barrio cercano a Campo de Mayo tuvo que decidir por dónde correr. ¿Podría correr por adentro de Campo de Mayo sin sufrir algún peligro? Frente a la duda, al principio corrió alrededor de una plaza ubicada frente de su casa, pero una tarde nublada, escuchó un helicóptero militar y decidió salir a correr atrás de él cuando todos en su casa dormían. Y de repente se encontró corriendo alrededor de Campo de Mayo. Tras cuatro horas de correr alrededor del predio ve que se acerca a la meta, que está por llegar al final del perímetro y dar la vuelta completa. Pero justo en ese instante, una torcedura en el tobillo hace que, en vez de detenerse, involuntariamente acelere y se encuentre corriendo una segunda vuelta. La felicidad que iba unida a la meta queda atrás, mientras que él sigue corriendo. "Si no se detuvo es porque debe seguir, y es lo que hace", lee Bruzzone. En este instante en el que como espectadores nos angustiamos por ese corredor que no puede parar de correr alrededor de Campo de Mayo, Bruzzone nos sigue leyendo su ficción y agrega que puede ser que haya otras opciones. Que quizás el corredor se ejercitaba alrededor de la plaza o que el corredor nunca corrió y sólo leyó Nacidos para correr y se imaginó todo lo demás.

En la ficción del corredor-como ocurría en la performance- hay repetición de la vuelta, hay una obsesión por seguir y hay desvíos. Podríamos pensar que se trataría de una especie de pulsión por correr, porque el gesto del corredor, que lo hace seguir adelante, es involuntario. Pero esa pulsión es acompañada de otras posibilidades. Como ocurría en la serie de libros infantiles Elige tu propia aventura, podemos escoger otras opciones. Esas múltiples posibilidades que plantea el narrador abren la puerta a otras historias posibles. En esa apertura hacia el futuro, la repetición se ubica del lado del deseo y no del de la pulsión. Y por eso posibilita elaboraciones del pasado.

En la performance, realidad y ficción se entrecruzan de un modo diferente a como lo hacen en la literatura. La performance le permite a Bruzzone poner el cuerpo en la escena y producir una repetición, un retorno, una vuelta más, que implica una diferencia. Montar en escena el acto cada vez es una manera de seguir corriendo alrededor del predio en el que estuvo viva por última vez su madre desaparecida. Bruzzone sabe que los desvíos no lo conducen hacia un objetivo preciso, pero eso no es lo que importa. Lo importante es continuar. El corredor sabe que la meta quedó atrás pero aun así no puede -ni quiere- detenerse. Las figuras de Campo de Mayo como imán y del corredor como un elemento imantado, conforman un modo de entender

\footnotetext{
22 No se puede dejar de mencionar que esta escena de dobles remite a la operación de duplicación del yo realizada por Albertina Carri en su film documental Los rubios (2003). Allí la actriz Analía Couceyro actuaba de Albertina Carri mientras esta última la dirigía, apareciendo las dos en escena.
} 
los vínculos entre pasado y presente, que exhibe la tensión entre lo que el sujeto quiere y puede saber, entre lo que quiere y puede hacer. Porque el corredor, que parece satisfecho por su iniciativa deportiva, en lugar de alcanzar una supuesta meta se encuentra con que no puede dejar de repetir la vuelta alrededor de Campo de Mayo. Pero tal como insiste LaCapra (2006) ciertas repeticiones son del orden de un trabajo del duelo, constituyéndose en actos de memoria conscientes y deliberados, a diferencia de un modo de la repetición que sería del orden de la pulsión de muerte involuntaria. En un sentido similar, Robin entiende el vínculo entre posmemoria y repetición: "Precisamente, para la posmemoria, el pasado no se ha convertido en un 'puro pasado', ni mucho menos. Las obras creadas constituyen un espacio transicional donde ese pasado es revivido, 'reexperimentado', y donde esa nueva representación permite no quedar fascinado, alucinado por ello, sino ser parte activa de ello en la conciencia del alejamiento" (2012: $352)$.

La especificidad del caso argentino que fue unido a un fuerte "no saber" sobre la muerte y el destino de los progenitores, supone especificidades en el proceso de elaboración de la pérdida y el duelo por parte de los hijos y los familiares. La desaparición "es una categoría que implica una presencia-ausencia que se mantiene a lo largo del tiempo, a pesar del conocimiento racional de la muerte de los desaparecidos" (Kordon y Edelman, 2007: 76). En Campo de Mayo cada nueva vuelta del corredor, como cada nueva puesta en escena de la performance, es igual a la anterior, pero es también diferente, porque es otra. Si cada vuelta implica un retorno, que podría vincularse con la continuación del daño, también supone una diferencia, un desplazamiento creativo. La performance le otorga a Bruzzone la posibilidad de un regreso descentrado. Montar la escena una y otra vez, no es otra cosa que seguir buscando.

\section{APUNTES FINALES: SOBRE LA REPARACIÓN}

En 2017 se colocó una baldosa que recuerda a la madre de Félix Bruzzone (Marcela Bruzzone Moretti) en la escuela en la cual estudió, el Instituto en Lenguas Vivas Juan Ramón Fernández, en el barrio de Recoleta en la Ciudad de Buenos Aires. Bruzzone leyó un texto en el acto de colocación, en el que reflexionaba sobre las posibilidades de reparación que ese tipo de acontecimientos permite a los amigos y familiares de desaparecidos. Si primero desconfía de la posibilidad de que algo alguna vez pueda ser reparador ("Es obvio que nada va a ser nunca mi madre", dice), luego nos invita a pensar la escena a partir de la figura de un "reparador de batidoras".

La del reparador de batidoras poniendo todo de sí para que la batidora vuelva a funcionar no es una mala imagen. Y tampoco es una mala imagen la de todos nosotros ayudando a hacer esta baldosa-baldosón. Como si lo reparatorio no fuera la baldosa-baldosón, sino todos nosotros construyéndola y viniendo a pegarla hoy acá. Esa sí podría ser una imagen reparatoria. O Lo reparatorio. (...) Nunca vi a mi mamá en acción, o no la recuerdo. Y ahora los veo a ellos y puedo decir, un poco, abrazado al reparador de batidoras, gracias baldosa-baldosón, ya está, ya la vi. (Bruzzone, 2017).

Es posible leer Campo de Mayo a través de esta idea del reparador de batidoras. Algo de aquello que Bruzzone denomina "lo reparatorio" sucede en cada puesta en escena de la conferencia performática. El proceso de conexión entre quienes están en el escenario y el 
público implica una apertura hacia los otros, que supone una expansión desde un trabajo de posmemoria familiar hacia uno afiliativo. En el encuentro que se da en cada nueva puesta en escena se construye memoria y se recuerda con otros. Otros que somos los espectadores y que es también su asistente, aquél en el que él se apoya y se duplica. Es por eso que Bruzzone repite la performance. La experiencia de poner el cuerpo en el escenario le permite un encuentro con otros en la construcción de la memoria de sus padres, que es la memoria de los años setenta en Argentina. Campo de mayo se constituye así en un objeto de transmisión de la memoria cultural porque a través de un acto de memoria familiar, personal y autoficcional habilita un trabajo de memoria colectivo. 


\section{BIBLIOGRAFÍA}

Amado, Ana. (2004). "Órdenes de la memoria y desórdenes de la ficción". Amado, Ana y Domínguez, Nora (comps.). Lazos de familia. Herencias, cuerpos, ficciones. Buenos Aires: Paidós.

ARFUCH, Leonor (2007). El espacio biográfico. Dilemas de la subjetividad contemporánea. Buenos Aires: FCE.

ARFUCH, Leonor (2008). "Memoria y autobiografía". Crítica cultural entre política y poética. Buenos Aires: FCE.

AREnes, Carolina y Pikielny, Astrid (2016). Hijos de los 70. Historias de la generación que heredó la tragedia argentina. Buenos Aires: Sudamericana.

BARTHES, Roland (2005). La cámara lúcida. Notas sobre la fotografía. Buenos Aires: Paidós.

BASILE, Teresa. "La orfandad suspendida: la narrativa de Félix Bruzzone". CELEHIS-Revista del Centro de Letras Hispanoamericanas 32 (2016): 141-169.

BLEJMAR, Jornada; Fortuny, Natalia. "Introduction", dossier: "Revisiting postmemory: The intergenerational transmission of trauma in post-dictatorship Latin American culture". Journal of Romance Studies 3 (2013): 1-5.

BlejMAr, Jordana (2017). Playfull memories. The Autofictional Turn in Post-Dictatorship Argentina. Palgrave Macmillan.

BRuZzone, Félix. “¿Qué repara una boldosa-baldosón?” Diario Página 12 (2017).

BruZzone, Félix (2007). 76. Buenos Aires: Tamarisco.

BRUZzone, Félix (2008). Los topos. Buenos Aires: Mondadori.

BRuZzone, Félix (2010) Barrefondo. Buenos Aires: Mondadori

BruZzone, Félix (2014) Las chanchas. Buenos Aires: Random House. Mondadori

BruZzone, Félix (2017) Piletas. Buenos Aires: Excursiones.

CiAnCiO, Belén. “CCómo (no) hacer cosas con imágenes? Sobre el concepto de posmemoria”. Constelaciones 7 (2015): 503-515

COBAS CARRAL, Andrea. "Narrar la ausencia. Una lectura de Los topos de Félix Bruzzone y de Diario de una Princesa Montonera de Mariana Pérez". Olivar 14 (20) (2013). ISSN 1515-1115.

CORBATTA, Jorgelina. "Psicoanálisis y literatura: La auto-ficción". VII Congreso Internacional Orbis Tertius de teoría y crítica literaria. 2009. La Plata: FAHCE. Acceso: 01/09/2016

Dalmaroni, Miguel (2004) La palabra justa. Literatura, crítica y memoria en la Argentina, 1960-2002. Mar del Plata: Melusina

Doubrovsky, Serge. (2012) “Autobiografía / verdad /psicoanálisis”. CASAS, Ana. (ed.) La autoficción. Reflexiones teóricas. Madrid: Arco.

FANDIÑO, Laura (2016) Acomodar la vida sobre esa arena tan movediza: las memorias de los hijos en la literatura de Argentina y Chile. Córdoba : Universidad Nacional de Córdoba 
ForNÉ, Anna (2014) "Reflexiones en torno a dos gemelos conceptuales: posmemoria y autoficción", SÖHRMAN, Ingmar, Vajta, Katharina (eds.) La langue dans la littérature, la littérature dans la langue: textes réunis en hommage à Eva Ablstedt. Göteborg: Acta Unversitatis Gothoburgensis

FrEUD, Sigmund ([1920] 2007). "Más allá del principio de placer". Obras completas. Volumen XVIII. Buenos Aires: Amorrortu.

FORTUNY, Natalia (2014). Memorias fotográficas. Imagen y dictadura en la fotografía argentina contemporánea. Buenos Aires: La Luminosa.

Gamerro, Carlos (2015). Facundo o Martín Fierro. Buenos Aires: Sudamericana.

GENETT, Gerard (1989). Palimpsestos. Madrid: Taurus.

HiRsCH, Marianne (1997). Family Frames. Photography, narrative and postmemory. Cambridge: Harvard University Press.

HIRSCH, Marianne (2012). The Generation of Postmemory. Writing and visual culture after de Holocaust. New York: Columbia University Press.

HIRSCH, Marianne. "Surviving images". The Yale Journal of Criticism 1 (2001): 5-37

HiRSCH, Marianne. “The Generation of Postmemory”. Poetics Today 29:1 (2008): 103-128

KAMENSZAin, Tamara (2016). Una intimidad inofensiva. Los que escriben con lo que bay. Buenos Aires: Eterna Cadencia.

KEIZMAn, Betina. "Las vidas que transcurren (una lectura de la performance Campo de Mayo de Félix Bruzzone)”. TRANS- Revue de littérature générale et comparée 19 (2015). DOI: 10.4000/ trans.1198

KORDOn, Diana y Edelman, Lucila (2007). Por-venires de la memoria. Buenos Aires: Ediciones Madres de Plaza de Mayo.

LACAPRA, Dominick (2006). Historia en tránsito. Experiencia, identidad, teoría crítica. Buenos Aires: Fondo de Cultura Económica.

LOGIE, Ilse. "Más allá del "paradigma de la memoria": la autoficción en la reciente producción posdictatorial argentina. el caso de 76 (Félix bruzzone)". Pasavento. Revista de estudios Hispánicos 1 (2015): 75-89.

MANDUCA, Ramiro y PROAÑo GÓMEZ, Lola (2017). “Intentos múltiples para la imposible recuperación de la memoria. Campo de Mayo. Una conferencia performática de Felix Bruzonne (2016)". ProAÑo GómeZ, Lola y VERZERo, Lorena (comp.). Perspectivas políticas de la escena latinoamericana Diálogos en tiempo presente. Buenos Aires-Los Ángeles: Editorial Argus-a: 233-240.

OBERTI, Alejandra (2015). Las revolucionarias. Militancia, vida cotidiana y afectividad en los setenta. Buenos Aires: Edhasa.

PeLLER, Mariela (2015). "La historia de las niñas. Memoria, ficción y transmisión en la narrativa de la generación de post-dictadura en Argentina”. EsCOBAR, Luis; GIORDANO, Juan; 
PiTTALUGA, Roberto (comp.) Figuraciones estéticas de la experiencia argentina reciente. Santa Fe: María Muratore

PeLLER, Mariela (2016) "Lugar de hija, lugar de madre. Autoficción y legados familiares en la narrativa de hijas de desaparecidos en Argentina”. Revista Criação \& Crítica 17 (2016): 75-90.

PÉREZ, Mariana Eva. “Their lives after: Teatre as testimony and the so-called 'second generation' in post-dictatorship Argentina”. Journal of Romance Studies 3 (2013): 6-16.

POZZI, Pablo (2001). Por las sendas argentinas...El PRT-ERP y la guerrilla marxista. Buenos Aires: Imago Mundi.

PREMAt, Julio. "Bruzzone y el deseo de literatura". HeLix 10 (2017): 214-233.

RoBIN, Régine (1994). Identidad, memoria y relato. La imposible narración de sí mismo, Buenos Aires: UBA.

RoBIN, Régine (2002). "La autoficción. El sujeto siempre en falta". Arfuch, Leonor. Identidades, sujetos y subjetividades. Buenos Aires: Prometeo.

RoBIN, Régine (2012). La memoria saturada. Buenos Aires: Waldhuter Editores.

SANFELIPPO, Luis. "Versiones del Trauma: LaCapra, Caruth y Freud", Historiografias 5 (2013): $51-70$

SARLO, Beatriz (2012). "Condición de búsqueda". Ficciones argentinas. 33 ensayos. Buenos Aires: Mardulce.

Sarlo, Beatriz (2005). Tiempo Pasado: Cultura de la Memoria y Giro Subjetivo. Buenos Aires: Siglo Veintiuno.

SzurmuK, Mónica (2009). "Posmemoria”. Szurmuk, Mónica; Mckee Irgwin, R. (coord.) Diccionario de estudios culturales latinoamericanos. México: Instituto Mora/Siglo XXI.

TAYLOR, Diana (2012). Performance. Buenos Aires: Asunto Impreso.

TAYLOR, Diana; FuENTES, Marcela (Eds.) (2011). Estudios avanzados de performance. México: FCE, Instituto Hemisférico de Performance y Política, Tisch School of the Arts, New York University.

VeCCHIOLI, Virginia et al. (2016). “Centros Clandestinos: de su desaparición a su reconstrucción virtual. La experiencia museográfica sobre el CCD El Campito, Guarnición Campo de Mayo". Actas del IX Seminario Internacional Políticas de la Memoria.

YACCAR, María Daniela. "Me interesaba explorar lo cotidiano”. Diario Página 12 (2016). 